\title{
STRATEGIC PLANNING AND ORGANIZATIONAL FLEXIBILITY IN TURBULENT ENVIRONMENTS
}

\section{Introduction}

The competitive landscape has been shifting impressively in the last three decades. Globalization, rapid technological changes, codification of knowledge, the Internet, talent and employee mobility, increased rates of technology transfer, the emergence of new customer needs and the innovation of products and business models: all these factors contributed to increase industry turbulence (Doz and Kosonen, 2008a; Roveda and Vecchiato, 2008). In a chaotic world in which markets and entire industries continuously emerge, collide, split evolve, and die, one of the primary determinants of success is the ability of the firm to cope with growing uncertainty, by sensing, seizing and handling external changes (Teece, 2007).

Various foresight practices and techniques ('strategic - or corporate - foresight') have been developed to support strategic planning in fast-paced environments and thus help decision makers cope with uncertainty (Battistella and De Toni, 2011; Rohrbeck and Gemunden, 2011; Vecchiato and Roveda, 2010a). The best-known and most-used are environmental scanning, scenario analysis, real options analysis, and product and technology roadmapping (Boyd and Fulk, 1996; Courtney, 2001; Schoemaker, 1993). These practices and tools are designed to identify drivers of change in the company's outside environment and investigate their likely evolution and impact on the organization. However, their theoretical foundations have been recently criticized by some leading management scholars, who highlighted the impossibility of forecasting with any acceptable degree of reliability. Even if forecasts might be accurate in the 
short term, they are not likely to be reliable in the long run as political, economic, social and technological drivers of change interact in novel and unforeseeable ways (Galbraith and Merril, 1996; Eisenhardt et al., 2010). These scholars thus supported reactive approaches based on ‘organizational flexibility’ and ‘strategic agility’ instead of planning and foresight-based approaches (Mintzberg, 1990; Wiltbank et al., 2006).

This paper explores how strategic planning and foresight (vs. organizational flexibility) might enhance the performance of firms - we ask: whether and under which circumstances do planning and foresight-based approaches help strategic decision makers keep their organizations aligned with changing environments? Under which circumstances should they emphasize flexible approaches instead? Our research design is a multiple-case inductive study focused on two large international corporations - Shell in the energy industry and Nokia in the mobile communication industry - which have recently placed great reliance on planning and strategic foresight for facing major changes in their business environment.

This paper contributes to the strategic management literature in two basic ways. First, it deepens our understanding of environmental uncertainty (Davis et al., 2009; Vecchiato, 2012b). Second, it provides descriptive data on the planning and foresight approaches that some of the world's largest and most influential companies used throughout the 2000s for remaining aligned with their fast-paced environments. More generally, this research expands our understanding of a fundamental issue in literature on management and foresight: how can a firm craft its strategy in a fast-changing business?

\section{Fast-paced Environments, Uncertainty and Strategic Decision Making}


Environmental uncertainty has been for a long time a key issue in literature on organization and innovation management. It arises when managers do not feel confident that they understand what the major events or changes in their industry are (Knight, 1921; Duncan, 1972; Loveridge and Saritas, 2012).

Growing uncertainty represents a key challenge for strategic planning - systematic and formalized approaches to strategy formulation - by affecting the foundation of strategic planning itself: the ability to collect sufficient and accurate knowledge about the firm's likely future operational environment (Ansoff, 1991; Porter, 1980). The challenge of making strategy under increased uncertainty has encouraged the design and refinement of specific practices and techniques which today are commonly used in a wide set of industries. Scholars developed forecasting tools for managing uncertainty at the level of innovation projects (Chapman and Ward, 1996; De Meyer et al., 2002) and capital budgeting and capital structure policies (Bromiley, 1986; Graham and Harvey, 2001; Leland, 1998). More generally, scholars developed future-oriented tools aimed at enhancing decision-making at the level of business and corporate strategy (Alsan and Oner, 2003; Fink et al., 2004; Porter et al., 2004). Some of the most popular techniques are environmental scanning, product and technology roadmaps, scenarios and real options (Porter et al., 2004; Voros, 2001).

Today the term 'corporate foresight' and 'strategic foresight' have become widely common for encompassing such future-oriented practices and techniques (Rohrbeck, 2012; Rohrbeck and Schwarz, 2013; Hirsch et al., 2013; Vecchiato, 2012a; Vecchiato, 2012b). However, strategic foresight had only uneven success so far. Increasing criticism has pointed to the impossibility of making reliable enough predictions: while relatively accurate in the short term, forecasting accuracy diminishes in the medium and long term as political, economic, social and 
technological drivers of change interact in novel and unforeseeable ways (Galbraith and Merril, 1996; Eisenhardt et al., 2010). Prominent scholars supported the idea that the best way to handle an uncertain future is actually to ignore it and avoid planning approaches (Hamel, 2000; Prahalad et al., 1998) and emphasized 'adaptive approaches' based on strategic agility and flexibility (Doz and Kosonen, 2008a). Adaptive approaches prescribe avoiding prediction as much as possible, but focussing rather on responding to change events as they emerge, and so stress continuous experimentation and quick reaction to changing environments (Mintzberg, 1990; van der Hejden et al., 2002).

The main goal of this paper is to explore whether and how strategic planning and foresight approaches (vs. organizational flexibility and adaptive approaches) enhance the competitive advantages of firms. Despite the interest on strategic foresight, we still know little about its concrete impact and value. Thus, there is a great opportunity to develop a more complete and rich understanding of strategic decision making under uncertainty. We seek to extend current theory and create new insights by exploring the effects of foresight efforts in two large corporation that recently faced huge discontinuities. We ask, whether and how do strategic planning and foresight-based approaches help decision makers cope with changes in the business environment? Under which circumstances are flexible approaches more helpful instead?

\section{Methods and Data}

Given the gap in the literature and the open-ended nature of our question, we adopted the case study methodology as the most useful, given its strength for theory building (Yin, 2003). We 
used an inductive, multiple case research design, as multiple cases permit a replication logic in which comparisons clarify whether emerging findings and inferences drawn from one case are confirmed or disconfirmed by results from the others, and also create more robust theory, because propositions are more deeply grounded in varied empirical evidence, and research questions and theoretical propositions more broadly explored (Eisenhardt, 1989).

We explored how Royal Dutch Shell PLC (Shell hereinafter) and Nokia coped with major changes in the energy industry and the mobile communication industry between the late 1990s and the late 2000s. These cases are extremely explanatory: on one hand, Shell and Nokia operated in distinct industries that underwent considerably different kinds of drivers of change and conditions of uncertainty. On the other hand, Shell and Nokia started long ago to systematically engage in foresight practices and techniques, and thus progressively designed and refined their approaches to handling environmental uncertainty. Shell is commonly recognized as the foremost exponent of scenario planning within the oil industry and the corporate sector in general (Grant, 2003), while Nokia is similarly noted for the scanning and roadmapping activities it used for trying to anticipate changes in the dynamic communication industry (Karkkainen and Ojanpera, 2006; Vecchiato and Roveda, 2010) .

We focused in particular on two sources of uncertainty - respectively, the emergence and establishment of Russia as a key player in the international oil and gas production markets (late 1990s - today) and the convergence of mobile phone and digital industries (games, imaging, music, Internet: early 2000s - today). Both these drivers of change turned to have a strong influence on Shell and Nokia respectively and were major foci of their corporate foresight activities. 
As these firms achieved very different results in the long run in terms of profits and competitiveness, they represented 'polar types' which allowed us to more clearly observe contrasting patterns in the data. Table 1 provides an overview of our empirical setting.

\section{'Insert Table 1 here'}

The unit of analysis was twofold. On the one hand, we examined the historical evolution and the main drivers of change in the energy industry and the mobile communication industry since the early 1990s. On the other hand, we analyzed the foresight actions of Shell and Nokia and the ways these actions contributed to the long term competiveness of each firm.

Data were collected through the combination of various sources and throughout an iterative process. First, we collected publicly available data, including annual reports, financial analysts’ reports, conference presentations by top managers, and articles and prior studies in the business press and scientific journals. In the case of Shell in particular, we were greatly aided by prior historical work of former managers and heads of scenario planning (Cornelius et al., 2005; de Geus, 1997), while in the case of Nokia by prior historical work of former managers and relevant scholars on the evolution of the company and the mobile phone industry (Doz and Kosonen, 2008b). Company archives such as internal memos and technical papers supplemented publicly available data. Second, we interviewed a sample of senior and mid-level managers, in particular the heads of the organizational units in charge of designing and implementing strategic foresight techniques and processes. We also interviewed external consultants who were involved in such processes and a sample of leading experts from academia and the industrial sector who had extensive knowledge of either Shell and the energy business or Nokia and mobile communication industry. 
Data analysis was highly iterative and used traditional approaches for inductive research (Eisenhardt and Graebner, 2007). We began with an in-depth study of each case through the lens of our research questions: whether and how do strategic planning and foresight-based approaches help decision makers cope with changes in their business environment? Under which circumstances are flexible approaches more helpful instead?

We initially analysed the cases independently one from the other to form a view for each one of them. We developed an understanding of the drivers of change that were faced by each firm, the tools and practices that were used to cope with these drivers, the outputs of these tools and the major decisions that were derived. We used tables and analytical notes to facilitate this process and sum up the main findings and early interpretations (Miles and Huberman, 1994). We turned afterwards to cross-case analysis, through which the insights and early propositions that emerged from each case were compared with those from the other, in order to identify consistent patterns and issues. We followed an iterative process of cycling among theory, data, and extant literature on industrial change and strategic decision making to refine our findings, relate them to existing theories, and clarify our contributions (Eisenhardt, 1989).

\section{Results}

In this section we illustrate what key drivers of change Shell and Nokia had to face, their methodological and organizational approaches to cope with these changes, and their long term performances.

\subsection{Shell and the Energy Industry}


Over the last two decades a large number of drivers of change contributed to raise uncertainty in the oil and gas industry (Vecchiato, 2012c; Vecchiato and Roveda, 2010b). The most relevant of these drivers were: (1) the collapse of the Soviet Union and the emergence of Russia in the energy industry; (2) the growing power of the supplier countries (Organization of the Petroleum Exporting Countries [OPEC]); (3) the rise of state-owned companies such as Saudi Aramco, Kuwait Oil, Petroleos de Venezuela and Gazprom from oil producing countries; (4) the rise of new majors such as Italian ENI, French Total, and Japanese Nippon Oil from industrialized countries; (5) the increasing concern for pollution and ecological sustainability of economic development, and the increasing demand for "clean” energy; (6) the first and the second Iraq war; (7) the increasing nationalism in Russia and Venezuela; (8) the economic growth of a number of large emerging countries (China, India, Russia, and Brazil); and (9) the recent global financial crisis.

In this context Shell relied extensively on scenarios as the main tool for addressing industrial change and environmental uncertainty. The scenario building process involved the following steps: (1) pointing out (fixing) the key decisions faced by the organization in the time horizon of concern; (2) listing predetermined elements and trends; (3) identifying driving forces of change that could have an impact on the business and the organization; (4) identifying the likely evolution of drivers of change and the scenario logics; (5) building the scenarios' plots and narratives; (6) analyzing the industry structure that would prevail in each scenario; (7) defining implications for competition and sources of advantage; and (8) generating and evaluating options for strategic action.

The company first began making significant use of scenarios in 1972: of the six scenarios built then, one suggested that disruptions of oil supply could result in a sharp rise in prices, thus 
anticipating the oil crisis that took place only a year later. Scenarios were adopted widely throughout the company shortly afterwards, and have gradually evolved (over almost four decades) in terms both of their scope and how they are used. The initial focus in the 1970s - on the key variables relevant to the business, namely energy demand and oil prices - has widened to include the effects of economic and political events and trends. In the 1980s deeper analysis of social and environmental (ecological) changes was added, so that by 1987 Shell's scenarios filled three separate volumes on oil, energy and global trends in the macro environment.

Later on scenarios at Shell were framed around three different levels, from 'global' to 'focused' and 'project' scenarios. Shell global scenarios concern major forces in the macro environment which surround the energy industry and analyze their alternative paths of evolution: they holistically encompass politics, economy, ecology, society, technology (PEEST landscapes). For instance, the Shell Energy Scenarios to 2050, released in 2008, described two possible worlds where political and social choices by governmental authorities strongly interact and concur to shape the demand and supply of energy and the effects on the physical environment:

'People are beginning to realize that energy use can both nourish and threaten what they value most - their health, their community and their environment, the future of their children, and the planet itself. These deeply personal hopes and fears can intensify and interact in ways that have different collective outcomes, and usher in the new energy era in very different ways.' (Shell energy scenarios to 2050: $p$ 10)

Former CEO Jeroen van der Veer introduced the Scramble and Blueprints scenarios derived from alternative paths of evolution of the drivers of demand, supply, and environmental concern:

'To help think about the future of energy, we have developed two scenarios that describe alternative ways it may develop. In the first scenario - called Scramble - policymakers pay little attention to more efficient energy use until supplies are tight. Likewise, greenhouse gas emissions are not seriously addressed until there are major climate shocks. In the second scenario - Blueprints - growing local actions begin to address the challenges of economic development, energy security and environmental pollution. A price is applied to a critical mass of emissions giving a huge stimulus to the development of clean energy technologies, 
such as carbon dioxide capture and storage, and energy efficiency measures. The result is far lower carbon dioxide emissions.' (Shell energy scenarios to 2050: p 4)

Based upon global scenarios, Shell ‘focused’ scenarios’ are built for addressing each business sector of the energy industry and each geographic area in which the firm operates. Focused scenarios shed light on the rise of new sources of competition by combining drivers of change in the macro environment with more specific market issues concerning the behaviour of rivals, suppliers, and customers. Focused scenarios tackle the impact of macro drivers of change on the competitive position of the organization and on the fungibility and adequacy of its current portfolio of assets. Finally, Shell 'project' scenarios investigate a particular investment decision by deriving the implications of global and focused scenarios and by gathering and processing more detailed information on competitors, price, profitability, technical, and managerial risk.

The case of the entry of Shell in the Russian market after the collapse of the Soviet Union (early 1990s) and the expansion of Shell's activities in the country in the last decade are very helpful to illustrate scenarios efforts and their impact on the long term performances of the company.

Shell's global scenarios saw the advent of Russia as an energy supplier as a huge opportunity to expand its gas operations. Specific country scenarios addressed Russia and its local institutional environment, setting the ground for the selection of different investment opportunities, which were assessed in turn by particular project scenarios encompassing highly related variables like local natural and morphological conditions, competitors' likely moves, etc..

As a result, Shell decided to engage in the Sakhalin II investment project in the early 1990s, establishing the Sakhalin Energy Investment Company (SEIC) to develop two fields - PiltunAstokhskoe and Lunskoe - off the coast of Sakhalin. The first was mainly an oil field and the 
second primarily a gas field with associated condensates - at the time they represented together the single largest integrated oil and gas field in the world. Shell's stake in the project was 55\%, and its partners were the Japanese companies Mitsui (25\%) and Mitsubishi (20\%). In June 1994 SEIC signed the PSA governing Sakhalin II with the Russian Government: among other important aspects, it provided for full cost recovery for SEIC investors and a royalty for the Russian government (in the form of gas) of $6 \%$ of the oil and gas produced over the life of the project.

Having gained this license Shell followed option theory to structure the project into two consecutive stages: the first (minor) phase - developing the Piltun-Astokhskoe field - started soon after in the mid 1990s. The development of the Lunskoe gas field - which represented the fundamental reason for SEIC's existence - started in 2003, with major scheduled investments expected to reach $\$ 10$ billion. The project involved building a LNG (liquefied natural gas) plant and an export terminal at the southern end of Sakhalin and pipelines to transport the natural gas and oil produced offshore in the north to these two facilities, which involved running the pipelines down through the whole island, crossing more than 1,000 rivers, several active seismic faults, and possibly unexploded war ordnance dating back 50 years [1].

The risks inherent in this bet had already been carefully evaluated in Shell's country and project scenarios, which highlighted the likelihood that the Russian government might seek to increase its profits and, despite the PSA deal, try to become more directly involved in Sakhalin II. Realizing this possibility, in the mid 2000s Shell was forced to consider new options for making its strategic position more robust and strengthening the stability of the project consortium and its operations. Together with its partners, the company signed an agreement in December 2006 that installed Gazprom as the leading shareholder in, and new operator of, the 
Sakhalin II project consortium. When the deal was eventually finalized (February 2007), the Russian giant had purchased a 50\%-plus-one-share stake from the original partners for a total sum of $\$ 7.45$ billion. Shell retained a $27.5 \%$ stake .

In this way, Shell gained the endorsement of the Russian government by aligning itself with the latter's interests and goals, as a Shell press release highlighted:

With LNG capacity effectively sold, Sakhalin II is moving to firmly establish its position in the global energy map as a reliable new source for customers. Through the Area of Mutual Interest (AMI) arrangement with Gazprom, the prospects for expansion of Sakhalin II through further LNG processing trains are enhanced [2].

while Gazprom deputy CEO Alexander Medvedev pointed out:

Gazprom's entry into Sakhalin II is a powerful impetus for implementation of this large scale development in the area of energy export to Asia pacific and North America. In turn, it will facilitate the company's strategy of phased entry into the global LNG market [3].

Thanks to its scenarios, the company had actually realized the crucial role of Russian government nationalism in the development and commercialization of the gas fields and moved quickly to finalize its partnership with Gazprom. The first gas exports from Sakhalin II to Japan thus early started in 2009 and the field reaching full capacity in 2010. As Andrei Galaev, CEO of the Sakhalin II consortium and senior manager of Gazprom said:

The Sakhalin-2 project is in the second year of the production phase. [...] The Russia's first LNG plant is up and running at its full rated capacity. We can say this in full confidence, for it is based on a solid track record of operation. We are now a reliable and fully-fledged energy supplier, commanding a 5\% market share in the global LNG market. In less than two years as a hydrocarbons producer, Sakhalin-2 has set an example in safety, state-of-the-art technology, and as a dependable supplier to energy markets in the Asia-Pacific[4].

Today, the Sakhalin II project has turned out to be a great commercial success for Shell. The ability of Shell to manage its operations and gain profits in Sakhalin is even clearer when 
compared with other foreign energy majors that tried to enter the Russia market. That's the case for instance of British Petroleum, an international major that suffered great struggles in Russia: in 2011, after a long dispute with Gazprom, the British company recently lost the property right and control of the Kovykta giant field of natural gas in East Siberia.

\subsection{Nokia and the Mobile Communication Industry}

Throughout the 2000s the mobile communication industry was affected by considerable shifts in technology and customer needs. The most remarkable of these shifts were: 2.5G (GPRS), 3G(UMTS), 4G (IMT-Advanced) wireless technologies and high-speed Internet access; W-LAN (WiFi and Bluetooth) for interoperability between different computational and electronics devices in a local area; convergence of multimedia technologies (e.g., music, imaging, games) into mobile communication; micropayments; global positioning system (GPS), and navigation systems; advances in hardware (microprocessor, display, battery, memory) and software (operating systems (OS), applications for mobile devices).

In this context, since 2001, under the umbrella of the yearly-based WorldMap Project, Nokia carefully started scanning emerging changes in technology and customer needs. Scanning activities covered the broadly defined information and communications technology (ICT) industry, not just the mobile phone industry. This involved a lot of external partners and both internal and external sources, including universities, consultants, and research centers. The resulting list of drivers of change underwent a first evaluation that aimed at selecting the most relevant ones that were able, at least potentially, to bring about disruptive shifts in the value chain and the boundaries of the business. The initial list of drivers was thus reduced to a considerably shorter one of about ten topics that made up the Nokia WorldMap. These topics 
were typically emerging technologies, business models, or other market opportunities that were relevant Nokia. Examples of topics that were included in the Nokia WorldMaps of the early 2000s were social networks, blogs, availability of communication for free.

However, efforts for coping with uncertainty went beyond environmental scanning and the identification of drivers of changes. Following the elaboration and the diffusion of the Nokia WorldMap, most efforts were devoted to the identification of the most suited 'owners' within the company and the promotion of their commitment to carry out explorative actions upon drivers of change. Such explorative actions consisted in defining new concepts of products and services, developing prototypes, commercializing them in target market niches and customer groups, promoting new venture projects, start-ups, and spin-offs, and building an internal forum for fostering dialogue among executives. On this regard, it is worth noting that since the early 2000s Nokia established dedicated units for carrying out venture activities, like the Nokia Growth Partners and Venture Partners. Environmental scanning and explorative actions kept strategic decision makers on top of new events and changes by involving them in a continuous learning process which aimed at figuring out the new activities of the value chain, defining the new players who were going to enter the business (e.g., software makers, web portals, record labels, publishers, moviemakers), and identifying the key issues and decisions to be faced for future growth.

Following environmental scanning, Nokia used technology and product roadmaps for planning the development of its product portfolio and defining its competitive position in emerging markets. Environmental scanning and explorative actions provided an essential input to the product and technology roadmaps, which involved managers and executives from several corporate and business units throughout the firm—-most importantly research, marketing, design, 
and strategy. The roadmap building process consisted in the following macro activities: (1) identifying the favorable paths of evolution of technologies, markets, and products and the main steps in these paths, that is to say the nodes of the roadmap; (2) defining the main attributes of each node, for example new product features and services, target performance for new features, and the time to launch of new products and services; (3) defining the causal and temporal relationships between the main steps of development of technologies, products, and markets, that is to say the links in the roadmaps; (4) specifying the main attributes of each link, for example the way to assemble technologies and the main partners to involve, and their role; (5) highlighting the value chain in different market segments, in relation to the revenue and cost structure and the way to deliver and capture value; and (6) highlighting the rising sources of competition.

As a result of these efforts, Nokia predicted that the process of convergence of digital industries into mobile communication would be very quick and would disrupt traditional mobile phones thanks to new functions and features inherent in imaging, music, gaming and software (Mobile Internet). Nokia thus developed and launched in the early 2000s its S60 Operating System (based on Symbian) which gave mobile phones the data processing capabilities typical of a personal computer, supporting the installation of a wide range of third-party software, such as MP3s and multimedia players, web browsers, games, office suites, and GPS navigation. At the same time Nokia made a major discontinuous change from traditional mobile phones by launching a whole array of new models onto the market: in particular its Nseries of 'smartphones' (launched in 2005) offered - thanks to the Symbian operating platform advanced computing capability and innovative mobile applications ('apps') and a wide range of multimedia and digital functions. 
However, despite the prompt launch and the early success of the Nseries, Nokia suffered a significant decline in profits and market share in the late 2000s, particularly in the emerging smartphone segment, due to the definitive boom of mobile Internet and mobile 'apps'. These drivers of change coincided with the rise of two new entrants into the mobile communication arena, which came from the personal computer (PC) industry and quickly became Nokia's major rivals: Apple, which launched its iPhone in 2007, and Google, which released its Android smartphone operating system in October 2008. In 2010 Apple's share of the smartphone segment reached 15.7\%, and sales of Android-equipped smartphones (from such manufacturers as Samsung, HTC, and Motorola) almost equaled those of Nokia’s Symbian-based devices by the fourth quarter of 2010 (Symbian's market share dropped from 52\% in 2008 to 32.6\% by the end ( $4^{\text {th }}$ quarter) of 2010, while Google Android's jumped from a mere 3.9\% in 2009 to $22.7 \%$ in 2010, and to nearly $30 \%$ by the final quarter)[5].

In the end, despite its foresight efforts, Nokia was not able to sustain its advantage over Apple and Google: as they entered the mobile Internet market in 2007 and 2008 respectively, both these companies - that could exploit the software skills they had originally developed in the PC industry - quickly established their iOS and Android operating systems over Symbian.

Nokia's foresight processes - which spurred the company to gamble its growth on its own Symbian operating system - turned out to be a source of inertia which, according to Jorma Ollila (Nokia's board chairman until 2012) made the company "too slow" to adapt to the smartphone revolution [6].

The comparison of Nokia and Samsung is very illustrative. In the late 2000s Samsung based its strategic response to the rise of mobile Internet on a purely reactive approach: the Korean company concurrently embraced different operating systems, i.e. Nokia’s Symbian, Google’s 
Android, Microsoft Windows Phone and its own Bada. But through the launch of the Galaxy product family in 2009, Samsung finally jumped on Android's bandwagon as this proved to be the fastest-growing operating system in the market - at the time Nokia was still focusing all its efforts on Symbian.

As a result of these struggles, Nokia entered in 2011 into a broad strategic partnership with Microsoft - the other longstanding software leader in the PC industry - under which Windows Phone replaced Symbian as the primary operating system for its smartphones. Two years later (September 2013) Nokia finally sold its mobile device division to Microsoft.

\section{A Framework for Industrial Change, Strategic Foresight and Organizational Flexibility}

In prior sections, we sketched the planning and foresight-based approaches that major companies adopted throughout the 2000s to face the increasing uncertainty of the energy and mobile communication industries. Table 2 sums up our findings.

\section{'Insert Table 2 here'}

Our data suggest two different classes of drivers of change, having a strong influence on the kind of uncertainty firms might face and the most suitable approaches to handling it. More generally, our findings offer the broad outline of a theoretical framework for selecting and using planning (foresight) approaches vs. flexible approaches, which we illustrate in this section.

A clear issue is essential for profitably using foresight techniques for addressing uncertainty: such issue regards the identity of the main activities of the value chain and the identity of the main components of the industry, i.e. rivals, suppliers, customers, substitute products, potential entrants. Such identity is exactly what we define as ‘boundary uncertainty’. 
The energy and the mobile communication businesses are well suited to illustrate what boundary uncertainty is. Let's consider the oil and gas business first. Since the early 1990s, key drivers of change - in particular, the collapse of the Soviet Union which opened the doors to foreign investors and the increasing nationalism of the Government after the rise of Putin - had a strong influence on the industry structure and the evolution of the main components of the business. Such influence concerned for instance the weakening of the power of the traditional international majors ('The Seven Sisters') and the rise of state-owned companies like Gazprom in Russia. However, these drivers of change did not affect the boundaries of the energy business. Over the last two decades, Shell's decision makers could be quite confident about the identity of: i) competitors - the other 'sisters' and the emerging the state-owned companies from producing countries; ii) suppliers_-OPEC and new emerging countries like Russia and Venezuela; iii) customers - firms and citizens of the most industrialized countries and the emerging ones; iv) providers of substitute products—renewables, nuclear, or hydrogen-based energy products and infrastructures. Shell's managers could be quite confident as well of the main activities of the value chain, consisting in the exploration, production, refining, and distribution of oil and gas. What Shell's executives could not know in the face of drivers of change in their business environment - in particular, the rise of Russia and the increasing nationalism of its Government was how these drivers would evolve, how they would affect the competitive position of the firm, and what responses they could adopt.

On the other hand, drivers of change in the mobile communication business affected the identity itself of the main components of the industry and thus brought about exactly 'boundary uncertainty'. Let's consider in particular such a driver of change as the convergence of digital technologies: digital imaging has turned the mobile phone into a kind of camera; digital music 
has turned it into a kind of MP3 player; games have turned it into a sort of PlayStation; GPs into a navigator; and finally mobile Internet into mini PCs. Coping with such drivers of change, required not only to investigate their likely evolution and impact on the organization but first of all to respond to the following questions: Who is in the business? Who are our competitors, suppliers, customers? What are the new kinds of products and services that customers want? What are the main activities of the value chain?

With the concept of boundary uncertainty as a backdrop, we distinguish between two main categories of drivers of change. The first is 'continuous' drivers of change that support and enhance the traditional identity of the main components of the industry, leading to incremental developments in the value chain, products and services. Continuous drivers of change typically affect mature and global industries where trajectories of technologies and customer needs are well-established, and stem from the macro environment (e.g., political and economical landscapes) which surround the industry. The second category is 'discontinuous' drivers of change that raise boundary uncertainty, by leading to completely new kinds of products, players, and activities of the value chain. Discontinuous drivers of change are typically disruptive technologies (Christensen, 1997; Adner, 2002) and new customer needs stemming from emerging or growing industries.

Continuous and discontinuous drivers of change - and thereby the rise or not of boundary uncertainty - entail very different implications for strategic decision making in turbulent environments. In case of continuous drivers that sustain the current boundaries of the business, managers of incumbent firms can be quite confident about the key decisions they have to make for sustaining their leadership in the long run. As a former head of scenario planning at Shell pointed out: 
'In our business everyone knew that at whatever future date there was a definitive key decision to be faced: the price of oil and gas. Whatever force in the external environment, managers had to assess the impact of this force on the future price of oil and gas. That's what the business is, and what you have always to think about.'

In this context, foresight techniques like scenarios could be used profitably for handling environmental uncertainty. Such techniques allowed Shell's managers to exploit what they had already learnt (and needed to know) about the boundaries of their business thanks to their past experience. Strategic foresight provided an organic and systematic framework for thinking about the likely evolution of (continuous) drivers of change (i.e., the increasing nationalism of the Russian Government) and the main components of their business (the threat inherent in the rise of Gazprom and its crucial role for exporting gas). As the former head of the scenario unit at Shell explained to us:

'In the energy industry, foresight techniques like scenarios work well because they help managers to gain new insight on the emerging forces that will drive the industry evolution. At the same time, as they dig into what they learnt from their past job, managers can think over the impact of these forces on their rivals, suppliers, and customers, and thereby on their company.'

Literature on cognition and organizational memory emphasizes that the ability of an organization to cope with changes in its external environment depends on the knowledge it had previously acquired through its own experience: as such experience has a degree of similarity with external changes, it provides a helpful basis on which the organization can rely for crafting its strategic response (Anand et al., 1998; Walsh and Ungson, 1991; Walsh, 1995). Since they don't affect the boundaries of the business and the identity of competitors, suppliers, and customers, continuous drivers of change allow exactly decision-makers to exploit their longstanding experience of their industry for trying to anticipate the future evolution of these drivers and thereby the future evolution of competitors, suppliers and customers themselves. The 
use of foresight (and planning) practices and techniques like scenarios thus turns out to be relatively simple and profitable.

On the other hand, by affecting the identity of the main components of the industry, discontinuous drivers of change require a completely new and different kind of knowledge from the one decision makers gained thanks to their previous experience. Let's consider again the convergence of multimedia technologies in the mobile communication business, and mobile Internet (and mobile apps) in particular. Of course such technologies entailed some key decisions such as the right applications to make available to consumers; but how could this decision be made before realizing that customers were going to use mobile phones as mobile PCs? Most of all, how could this decision be addressed before becoming fully aware of the identity of the new players entering the mobile communication business (i.e., Google and Apple)? How could managers coming from the traditional mobile communication arena cope with such challenge on the basis of their past experience and their knowledge of the previous boundaries of the business?

Under boundary uncertainty conditions, the key task for strategic decision makers is to identify the new value chain and the new components of the business. This is exactly what the Nokia WorldMap - environmental scanning efforts - and most of all its product and technology roadmaps failed to do: they failed to anticipate the entry of Apple and Google and thereby their implications for the company, i.e. the establishment of their operating systems for mobile devices.

Only if and when boundary uncertainty has been solved - and thereby decision makers have gained a sound grasp of the main components of their industry, firms might start using foresight techniques like scenarios or roadmaps. The full identification of the boundaries of the business 
serves exactly to fix the key issues for future growth, which is in turn a condition sine qua non

for strategic planning: the former head of scenario planning of Shell emphasized as well:

'Managers must look out for the right conditions for using predictive techniques like scenarios by weighing what these tools allow to learn about the future against what they require as their own input. If the key issues and challenges to be faced by the organization have not been properly defined yet, scenarios will lack focus and executives will be involved in a blinding process which actually mislead them and reduce their understanding of the future.'

In the case of discontinuous drivers of change which scramble the boundaries of a given industry, managers cannot rely on their previous knowledge of their business to fully anticipate the rise of new competitors, suppliers, product features, etc...; this turns out to be a very difficult task for foresight technique like roadmaps. This was exactly what happened at Nokia: they developed and pioneered Symbian and, through its early launch into the market, they bet on their ability to establish it as the standard platform for mobile Internet. However, later on Apple and Google actually entered the market and finally established their own operating systems. Strategic foresight efforts lead Nokia's decision makers to become confident and familiar with their wrong predictions about the future boundaries of their industry; this confidence in turn made Nokia unable to grasp the real future as long as it started emerging (e.g., Nokia underestimated the threat inherent in Apple’s iPhone and Google’s Android and kept on betting on Symbian).

Literature on management largely emphasized the role that the strategic beliefs that decision makers bear in their mind have in their responses to external changes (Walsh, 1995). As they turn out to be wrong - a risk which is really high in the case of discontinuous drivers of change early predictions about the future components of the business are likely to become a source of inertia rather than adaptation. Under boundary uncertainty, decision makers should emphasize thereby strategic flexibility and quick learning instead of planning and foresight, by focusing on new events as they emerge and preparing for quick move and reaction, like Samsung did as it 
promptly embraced Android. Decision makers might then start using and relying on foresight techniques once boundary uncertainty has been solved, so as to deepen the investigation of the likely evolution of 'discontinuous' drivers of change and their impact on the organization.

Summing up, we suggest that: 1) decision makers that face continuous drivers of change should emphasize strategic planning and use foresight approaches for addressing and anticipating the likely evolution of their industry; 2) decision makers that face discontinuous drivers of change and boundary uncertainty should emphasize strategic flexibility and learning, in order to grasp the new key components and players of their industry as soon as they emerge and adapt quickly.

\section{Discussion}

We add to the study of strategic decision making under uncertainty. We address a fundamental issue in strategic management: How firms should craft their strategy in fast-paced environments? (Rumelt at al., 1994). Despite the limitations of our case study research, some managerial and theoretical implications can reasonably be drawn. Our core contribution is the broad outline of a framework for strategic foresight vs. organizational flexibility in fast-paced industries.

Our main contribution is the improvement of our knowledge about the different kinds of uncertainty and drivers of change a firm might face in its business environment. The concept of 'boundary uncertainty' builds upon the work of previous scholars who emphasized the frequent emergence of new markets because of the increasing pace of technological change (Bettis and Hitt, 1995; Santos and Eisenhardt, 2009; Vecchiato, 2012a). As we explore the concept of boundary uncertainty and continuous vs. discontinuous drivers of change, we try to deepen our understanding of the value of strategic foresight versus strategic flexibility in coping with 
turbulent environments. We thus add to the long running debate between the 'planning' and the 'learning' schools of strategic management. On one hand, in the case of continuous drivers of change which do not bring about boundary uncertainty, our findings are consistent with the core tenet of the planning school - that an organization should try hard to predict changes and new events (Ansoff, 1991). On the other hand, our findings clearly show that in the case of discontinuous drivers of change which bring about boundary uncertainty, decision makers should stay flexible and emphasize agility, so as to adapt to changing situations as they develop (Mintzberg, 1990). In this context, there is the serious risk that such foresight practices and techniques like roadmaps become a source of inertia, locking decision managers into the (wrong) future they predicted and thus distracting them from the real future. Only once boundary uncertainty has been solved and decision makers have gained a sound grasp of the main components of their industry, they might fully rely on planning approaches and foresight techniques in order to deepen the investigation of the likely evolution of 'discontinuous' drivers of change and their impact on the organization.

In order to better understand the results of this research and their implications, it is worth to point out that scholars in the field of foresight and planning recently emphasized that the actual role of foresight techniques in fast-paced businesses is not to predict the future but to enhance exactly learning and flexibility (Cornelius et al., 2005; Grant, 2003; Vecchiato, 2012c; 2014). According to these scholars, foresight techniques foster the ability of the organization to sense and seize changes in the external environment.

On the one hand, our empirical research showed that product and technology roadmaps were not effective in the case of Nokia and the boundary uncertainty it faced because of the rise of mobile Internet. On the other hand, previous findings of scholars suggest that other foresight 
techniques, instead of roadmaps, might be still useful - even in the face of discontinuous drivers of change. This might be the case for instance of real options, as they allow the organization to prepare for alternative futures and at the same they do not require it to commit to any one of these futures - unless boundary uncertainty is solved. We thus suggest that the exploration of different foresight techniques and planning approaches under boundary uncertainty can be a promising avenue for future research. The key lesson we drew from the case of Nokia is that, in the face of discontinuous drivers of change, foresight techniques should be used to explore different value chains and industry structures - without committing to any one of these structures. In particular, Vecchiato (2014) suggests that the identification of first mover advantages is an essential condition in order to foresight efforts enhance the strategic agility of the organization: the exploration of possible linkages between foresight and the recognition of first mover advantages in the face of discontinuous drivers of change might be a very interesting avenue for future research.

\section{Conclusions}

Research setting, data collection and data analysis were designed in order to enhance the construct and internal validity of our theoretical framework; through data triangulation between different sources and through pattern-matching across cases we sought to strengthen the reliability and external validity of our conclusions (Eisenhardt and Graebenr, 2007). The considerable differences between Shell and Nokia, in terms both of their businesses and the kinds of uncertainty they faced, allowed to more clearly observe contrasting patterns in the data regarding the selection of foresight practices and techniques and at the same time enhanced the generalizability of our conclusions regarding their use for strategic decision making. On the other 
hand, it is critical to note that our work is based on two focal firms and thus on a limited number of cases. We selected our theoretical sample according to the main purpose of this paper that is as typical of case study research - to develop theory: the next step is empirical testing (Eisenhardt, 1989). Future research may build upon our work to explore the cases of other firms and investigate the role of strategic foresight versus flexible approaches in sustaining the performance of the organization in fast-paced environments (Teece, 2007). 


\section{Endnotes}

[1] LNG - Liquefied Natural Gas - is natural gas that has been temporarily liquefied for easy storage and transportation.

[2] “Gazprom enters Sakhalin II project”, Shell Media Center, April 18, 2007, available on www.shell.com.

[3] “Gazprom enters Sakhalin II project”, ibidem.

[4] Andrei Galev’s speech at Sakhalin’s major energy conference 2010: see “Sakhalin Energy CEO delivers message at Sakhalin Oil and Gas 2010" press release available on the website of the Sakhalin II Consortium www.sakhalinenergy.ru.

[5] Source: Gartner (July, 2011).

[6] Source: D. Thomas, Nokia missed smartphone 'revolution', The Financial Times, 2 May, 2012. 


\section{References}

Adner, R. (2002), "When are technologies disruptive? A demand-based view of the emergence of competition”, Strategic Management Journal, Vol. 23, pp. 667 - 688.

Alsan, A. and Oner, M.A. (2003), “An integrated view of foresight: integrated foresight management model", foresight, Vol. 5 No. 2, pp.33 - 45.

Anand, V., Manz, C. C. and Glick, W. H. (1998). “An organizational memory approach to information management”, Academy of Management Review, Vol. 23, pp. 796-209.

Ansoff, H.I. (1991), “Critique of Henry Mintzberg’s The Design School: reconsidering the basic premises of strategic management”, Strategic Management Journal, Vol. 12, pp. 449 - 461.

Battistella, C., and De Toni, A. F. (2011), “A methodology of technological foresight: A proposal and field study”, Technological Forecasting and Social Change, Vol. 78, pp. 1029 - 1048.

Bettis, R. A. and Hitt, M. A. (1995), “The new competitive landscape”, Strategic Management Journal, Vol. 16, pp. 7 - 19.

Boyd, B. K. and Fulk, J. (1996), "Executive scanning and perceived uncertainty: a multidimensional model”, Journal of Management, Vol. 22, pp.1 - 22.

Bromiley, P. (1986), Corporate Capital Investment: A Behavioural Approach, Cambridge University Press, New York.

Chapman, C. and Ward, S. (1996), Project risk management: processes, techniques and insights, John Wiley, Chichester.

Christensen, C. M. (1997). The Innovator's Dilemma. Harvard Business School Press, Boston, MA.

Cornelius, P., Van de Putte, A. and Romani, M. (2005), “Three decades of scenario planning in Shell”, California Management Review, Vol. 48, pp. 92 - 109.

Courtney, H. (2001), 20/20 Foresight: Crafting Strategy in an Uncertain World, Harvard Business School Press, Boston, MA.

Davis, J., Eisenhardt, K. M. and Bingham, C. (2009), “Optimal structure, market dynamism and the strategy of simple rules”, Administrative Science Quarterly, Vol. 54, pp. 413 - 452.

de Geus, A. (1997), The Living Company. Harvard Business School Press, Boston, MA.

De Meyer, A., Loch, C. H. and Pich, M.T. (2002). "Managing project uncertainty: from variation to chaos”, Sloan Management Review, Vol. 43, pp. 60 - 67. 
Doz, Y., and Kosonen, M. (2008a), Fast Strategy: How Strategic Agility Will Help You Stay Ahead of the Game. Wharton School Publishing, Philadelphia, PA.

Doz , Y. and Kosonen, M. (2008b). “The Dynamics of Strategic Agility: Nokia’s Rollercoaster Experience”, California Management Review, Vol. 50, pp. 95 - 118.

Duncan, R.B. (1972), “Characteristics of organizational environments and perceived Environmental uncertainty”, Administrative Science Quarterly, Vol. 17, pp. 313 - 327.

Eisenhardt, K. M, Furr, N. R., and Bingham, C. (2010), "Microfoundations of performance: Balancing efficiency and flexibility in dynamic environments", Organization Science, Vol. 21, pp. 1263 - 1273.

Eisenhardt, K. M. (1989), “Building theories from case studies research”, Academy of Management Review, Vol. 14, pp. 532 - 550.

Eisenhardt, K. M. and Graebner, M. E. (2007). "Theory building from cases: opportunities and challenges”, Academy of Management Journal, Vol. 50, pp. 25 - 32.

Fink, A., Siebe, A. and Kuhle J.P. (2004), "How scenarios support strategic early warning processes”, foresight, Vol. 6 No. 3, pp.173 - 185.

Galbraith, C.S. and Merrill, G.B. (1996), “The Politics of Forecasting: Managing the Truth”, California Management Review, Vol. 38, pp. 29 - 43.

Graham, J. R. and Harvey, C. R. (2001), “The theory and practice of corporate finance: evidence from the field”, Journal of Financial Economics, Vol. 60, pp. 187 - 243.

Grant, R. M. (2003), "Strategic Planning in a Turbulent Environment: Evidence from the oil majors”, Strategic Management Journal, Vol. 24, pp. 491 - 517.

Hambrick, D. C. (1982), "Environmental scanning and organizational strategy”, Strategic Management Journal, Vol. 2, pp. 159 - 174.

Hamel, G. (2000). Leading the revolution. Harvard Business School Press, Boston, MA.

Hirsch, S., Burggraf, P., Dahem, C. (2013), "Scenario planning with integrated quantification managing uncertainty in corporate strategy building”, foresight, Vol. 15, pp.363 - 374.

Karkkainen, P. and Ojanpera,T. (2006). "Pushing technology where the market will be: the case of Nokia”, International Journal of Technology Management, Vol. 34, pp. 203 - 216.

Knight F. H. (1921), Risk, Uncertainty, and Profit, Hart, Schaffner \& Marx, New York.

Lawrence, P.R. and Lorsch, J.W. (1967), Organization and Environment, Harvard University Press, Cambridge, MA.

Leland, H. E. (1998). “Agency costs, risk management, and capital structure”, The Journal of Finance, Vol. 53, pp. 1213 - 1243. 
Lieberman, M. B. and Montgomery D. B. (1988), “First-mover advantages”, Strategic Management Journal, Vol. 9, pp. 41 - 58.

Loveridge, D. and Saritas, O. (2012), "Ignorance and Uncertainty: influences on Future-oriented technology analysis” Technological Analysis and Strategic Management, Vol. 24, pp. 753767.

Mintzberg, H. (1990), “The design school: reconsidering the basic premises of strategic management”, Strategic Management Journal, Vol. 11, pp. 171 - 195.

Porter, A.L., Ashton, B., Clar, G., Coates, J.F., Cuhls, K., Cunningham, S.W., Ducatel, K., Van der Duin, P., Georghiou, L., Gordon, T., Linstone, H., Marchau, V., Massari, G., Miles, I., Mogee, M., Salo, A., Scapolo, F., Smits, R., Thissen, W. (2004), “Technology futures analysis: toward integration of the field and new methods", Technological Forecasting and Social Change, Vol. 71, pp. 287-303.

Porter, M.E. (1980), Competitive Strategy, The Free Press, New York.

Prahalad, C. K., O’Neal, D., Hamel, G. and Thomas, H. (1998), Strategic Flexibility: Managing in Turbulent Environments, Wiley, Chichester.

Rigby, D. (2001), "Management tools and techniques: A survey”, California Management Review, Vol. 43, pp. 139-160.

Rohrbeck, R. (2012), "Exploring value creation form corporate foresight activities”, Futures, Vol. 44, pp. 440 - 452.

Rohrbeck, R., and Gemünden, H. G. (2011), “Corporate Foresight: Its Three Roles in Enhancing the Innovation Capacity of a Firm”, Technological Forecasting and Social Change, Vol. 78, pp. $231-243$.

Rohrbeck, R., Schwarz, J. O. (2013), “The value contribution of strategic foresight: insights from an empirical study of large European companies”, Technological Forecasting and Social Change, Vol. 80, pp. 1593 - 1606.

Rumelt, R. P., Schendel, D. E. and Teece, D. J. (1994). Fundamental issues in strategy: A research agenda, Harvard Business School Press, Boston.

Santos, F. M. and Eisenhardt, K.M. (2009), "Constructing markets and shaping boundaries: entrepreneurial power in nascent fields", Academy of Management Journal, Vol. 52, pp. $643-671$.

Schoemaker, P. J. H. (1993), "Multiple scenario development: its conceptual and behavioural foundation”, Strategic Management Journal, Vol. 14, pp. 193 - 213.

Shell Energy Scenarios to 2050, available online http://www.shell.com/global/futureenergy/scenarios/2050.html 
Teece D. J. (2007), "Explicating dynamic capabilities: the nature and microfoundations of (sustainable) enterprise performance”, Strategic Management Journal, Vol. 28, pp. 1319 1350.

van der Heijden, K., Bradfield, R., Burt, G., Crains, G. and Wright, G. (2002), The Sixth Sense: Accelerating Organisational Learning with Scenarios, Wiley, Chichester.

Vecchiato, R. "Creating Value through Foresight: First Mover Advantages and Strategic Agility”, Technological Forecasting and Social Change, forthcoming

Vecchiato, R. (2012a), “Strategic Foresight: Matching Environmental uncertainty”, Technology Analysis and Strategic Management, Vol. 24, pp. 783 - 796.

Vecchiato, R. (2012b). "Strategic Foresight and Environmental Uncertainty: A Research Agenda”, foresight, Vol. 14, pp. 387-400.

Vecchiato, R. (2012c). "Environmental uncertainty, foresight and strategic decision making: an integrated study”, Technological Forecasting and Social Change”, Vol. 79, pp. 436-447.

Vecchiato, R. and Roveda, C. (2010a), "Strategic foresight in corporate organizations: assessing the effect and response uncertainty of technology and social drivers of change", Technological Forecasting and Social Change, Vol. 77, pp. 1527-1539.

Vecchiato R., Roveda C., (2010b), "Foresight in Corporate Organizations, Technology Analysis \& Strategic Management, Vol. 22, pp. 99-112.

Roveda C., Vecchiato R., (2008), "Foresight and Innovation in the context of industrial clusters: the case of some Italian districts", Technological Forecasting and Social Change, Vol. 75, pp. 817-833.

Voros, J. (2001), "Reframing environmental scanning: an integral approach”, foresight, Vol. 3 No. 6, pp. 533 - 551.

Walsh, J. P. and Ungson, G. R. (1991), “Organizational Memory”, Academy of Management Review, Vol. 16, pp. 57-91.

Walsh, J. P. (1995). "Managerial and organizational cognition: Notes from a trip down memory lane”, Organization Science, Vol. 6, pp. 280 - 321.

Wiltbank, R., Dew, N., Read, S. and Sarasvathy, S. D. (2006), "What to Do Next? The Case for non-Predictive Strategy”, Strategic Management Journal, Vol. 27, pp. 981 - 998.

Yin, R. K. (2003), Case Study Research: Design and Methods (3rd ed.) Sage, Newbury Park. 